\title{
Inland and Coastal Hydrographic Feature Identification in the Bahamas Using RADAR Data and Raster Processing in a GIS
}

\author{
Peter G. Chirico ${ }^{1} \&$ Katherine C. Malpeli ${ }^{1}$ \\ ${ }^{1}$ U.S. Geological Survey, Reston, VA, USA \\ Correspondence: Peter G. Chirico, U.S. Geological Survey, 12201 Sunrise Valley Drive, National Center \\ MS926A, Reston, VA 20192, USA. Tel: 1-703-648-6950. E-mail: pchirico@usgs.gov
}

Received: June 26, 2012 Accepted: July 9, 2012 Online Published: July 13, 2012

doi:10.5539/jgg.v4n3p29 URL: http://dx.doi.org/10.5539/jgg.v4n3p29

\begin{abstract}
Islands within the Caribbean region are frequented by heavy rains and strong winds, causing flooding and damage to infrastructure and the environment. The increasing availability of spaceborne RADAR data offers advantages over optical imagery for the mapping and mitigation of such hazards. RADAR data has the ability to penetrate cloud cover, making it capable of collecting data during virtually all weather conditions. In this study, the Advanced Land Observing Satellite (ALOS) Phased Array type L-band Synthetic Aperture RADAR (PALSAR) was used to distinguish seasonally dynamic water bodies on New Providence Island in the Bahamas using an image thresholding technique. The threshold was determined by performing statistics on field-validated training sites. The accuracy of the RADAR data's classification of water bodies was tested using a control dataset derived from GeoEye-1 imagery and GPS points collected during field work. The RADAR data was found to best classify large, static water bodies. It less accurately classified small, seasonally inundated water bodies and small ponds that are not spatially separated from vegetation. This study demonstrates a practical methodology which can be easily adapted by government and emergency management agencies within the Caribbean, as a preparation and mitigation tool. As such, it addresses the need for accessible data, techniques, and methods, designed to improve the understanding of dynamic natural phenomenon and assist government managers with decision making.
\end{abstract}

Keywords: PALSAR, RADAR, flood, threshold, Caribbean, Bahamas

\section{Introduction}

The Caribbean region is threatened by several types of natural hazards, most commonly tropical storms and hurricanes. The heavy rains and strong winds associated with such events have the potential to cause flooding and destroy infrastructural and environmental features. Flat, low-lying islands such as those within the Bahamian island chain are particularly vulnerable to the effects of flooding and storm surge. The islands of the Bahamas have suffered the effects of several tropical storms and hurricanes in the past decade. In October 2005, Hurricane Wilma passed through the northern islands of the Bahamas displacing approximately 1,500 people and damaging or destroying more than 200 homes. In September 2008, Tropical Storm Hanna swamped the Bahamas with heavy rain and strong winds. Days later, Great Inagua Island took a direct hit from Hurricane Ike, which again drenched the southeastern Bahamas. Most recently, in August 2011, Hurricane Irene struck the Bahamas as a category 3 storm, with the greatest amount of damage occurring on Acklins and Crooked Islands.

Remote sensing and satellite image interpretation offer a methodology whereby hazard and mitigation programs benefit from an increased capability to map, monitor, plan for, and mitigate the effects of natural hazards (Joyce et al., 2009). Historically, remote sensing data used for land cover analysis, flood hazard mitigation and response efforts, and change detection have relied heavily upon optical satellite imagery. While optical spaceborne sensors have the advantage of being an established and well-developed technology, they are limited to sensing short wavelengths and rely on solar radiation as the energy source. For all stages of the hazards cycle, from mitigation to recovery, the use of passive remote sensing data is limited by atmospheric conditions such as heavy cloud cover. Radio detection and ranging technology (RADAR), however, is an active remote sensing system capable of collecting data day-and-night and in virtually all weather conditions (Herold et al., 2004).

Few studies involving the application of remote sensing technologies for natural hazards and mitigation analysis exist in the Caribbean region. Many of the remote sensing studies that have been done in the Caribbean focus on 
utilizing optical sensors to study coral reefs, near-shore marine vegetation, and bathymetry (Mumby \& Harborne, 1999).

In this study, the Advanced Land Observing Satellite (ALOS) Phased Array type L-band Synthetic Aperture RADAR (PALSAR) data are used to distinguish areas of open water on New Providence Island in the Commonwealth of the Bahamas by creating training sites from optical satellite imagery, analyzing and classifying the backscatter coefficients of the PALSAR images, and using a combination of optical imagery and data control points to verify the results. This study tests the applicability of PALSAR data for identifying water features and uses raster-based GIS processing techniques to identify seasonally inundated areas as a tool for hazards mapping. While the ALOS satellite is no longer operational, data from the extensive PALSAR archive can be used as baseline pre-event imagery for the identification of seasonally inundated areas, as a component of flood hazard mitigation. This study demonstrates a practical methodology which can be easily adapted by government and emergency management agencies within the Caribbean, as a preparation and mitigation tool. As such, it addresses the need for accessible data, techniques, and methods, designed to improve the understanding of dynamic natural phenomenon and assist government managers with decision making.

\section{Background}

\subsection{Sensor Development}

The historical use of remote sensing data in flood hazard analysis has largely relied upon optical satellite imagery and the capabilities of such sensors to assist with basic research on flood hazards is well established. Showalter et al. (1999) provide an annotated bibliography of literature published from 1972 to 1999 related to the application of remote sensing technologies for detecting and analyzing natural hazards.

An alternative method of flood mapping relies onSynthetic Aperture RADAR (SAR) data. SAR systems operate by measuring the power of the radio wave signal sent to and received from the terrain surface from a satellite or airborne platform. The most commonly used wavelengths of imaging SAR systems are L-band (24 cm wavelength), C-band (5.6 cm wavelength), and X-Band (3 cm wavelength). Most SAR systems can transmit and receive signals in either one of two polarimetric configurations: horizontal waves $(\mathrm{H})$ and vertical waves $(\mathrm{V})$. The angle of the incident radio waves varies with each SAR sensor, but generally ranges from $20^{\circ}$ off nadir to $60^{\circ}$ off nadir (Ulaby et al., 1986). The resulting images derived from SAR have a spatial resolution ranging from $1 \mathrm{~m}$ to $100 \mathrm{~m}$.

\subsection{RADAR}

The standard RADAR equation helps to explain the variables which influence the brightness of the pixels in output RADAR images (Campbell, 2007). Traditionally the equation is expressed as:

$$
P_{r}=\left(\sigma G^{2} P_{t} \lambda^{2}\right) /\left((4 \pi)^{3} R^{4}\right)
$$

$P_{r}$ represents the energy returned to the RADAR sensor from the ground. $R$ defines the range to the ground target from the RADAR antenna. The power transmitted is shown by $P_{t}$ and the wavelength of the energy transmitted is expressed as $\lambda$. The RADAR sensor's ability to focus its energy on the ground target is defined as the antenna gain and is represented by $G$. Finally, $\sigma$ is the variable which is not set by the RADAR system itself and represents the backscatter coefficient. The backscatter coefficient is a measure of the scattering properties of features on the ground as compared to a cross-sectional area of a perfectly reflecting sphere $\left(\sigma^{0}\right)$ that would produce the same strength reflection as measured objects on the surface.

The RADAR cross-sectional area of an object does not necessarily bear a direct relationship with the physical cross-sectional area of that object. Rather, it depends on other factors such as the material properties of the object, the angle of the incident RADAR energy, the shape of the object, the object's relative size as compared to the wavelength $(\lambda)$ of the RADAR system, and the angle of the reflected energy back towards the sensor.

The backscatter coefficient is expressed in decibels $(\mathrm{dB})$ and measures the interaction of the RADAR system and the complex features within the landscape observed (Townsend \& Walsh, 1998). The observed ground surface is rarely uniform and is influenced by topography, soil moisture, vegetation, and other natural and man-made phenomenon.

One of the most significant contributing surface properties to the backscatter coefficient value is the roughness of the surface. While there are differing definitions of surface roughness, Campbell (2007) defines a common formula to calculate roughness as:

$$
S h>\lambda /(8 \cos \theta)
$$


As the standard deviation of the surface height $\left(S_{h}\right)$ increases above one-eighth of the wavelength $(\lambda)$ divided by the cosine of the incidence angle $(\cos \theta)$, the surface is considered to be rough. In general, three basic types of surface scattering mechanisms can be defined: (1) diffuse reflectors which correspond to features of variable roughness and are represented in RADAR images as a speckled gray appearance (2) corner reflectors which are extremely strong reflectors of the RADAR signal and often are bright in appearance, and (3) specular reflectors which are smooth surfaces from which the incident RADAR signal is reflected away from the sensor, causing the values to appear dark.

Interpretation of the RADAR backscatter coefficient is often best accomplished by interpreting the type of scattering present and correlating the scattering with the presence or absence of certain types or assemblages of land cover features.

\section{RADAR Remote Sensing Techniques}

SAR signals are ideally suited to determining the difference between land and water because flat water surfaces are often near perfect specular reflectors. RADAR signals have been successfully processed to map several types of land cover features, including open water, flooded forests, and coastal vegetation (Horritt et al., 2003). Fully polarimetric $\mathrm{C}, \mathrm{L}$, and P-band airborne RADAR were used to map forest, wetland, and agricultural ecosystems, but early studies showed limited utility with single polarization sensors (Pope et al., 1994). Studies using C-band and L-band spaceborne RADAR proved successful at delineating flooded and non-flooded forests in tropical environments (Hess et al., 1995). Further studies have demonstrated that RADAR can be used to discriminate between open water, bogs and alluvial and non-alluvial forests in tropical floodplains and the fact that both the RADAR backscatter values and the changes in backscatter values over time can be used to monitor flood dynamics (Martinez \& Le Toan, 2007). Coastal plain forested wetlands and hydroperiods have been mapped using a Principle Component Analysis (PCA) applied to C-band HH and VV ERS-2 and ENVISAT images (Lang et al., 2008). Studies concerned with the mapping of mangroves have also experimented with using RADAR data as a means of identifying this feature, and positive results are demonstrated when mangroves are spatially separated from other forest types, thus eliminating any confusion between mangrove classes and other types of vegetation (Lucas et al., 2007). A thorough review of the integration of stage data, hydraulic models, and remote sensing techniques for riverine flood detection is provided by Schumann et al. (2009). Notably absent in the studies reviewed are those which focus on islands subjected to rainfall and coastal inundation effects.

The integration of optical and RADAR remote sensing for land cover analysis has also been examined. By providing an additional portion of the electromagnetic spectrum, the integration of RADAR data can at times provide a clearer image, reduce the redundancy of optical bands, and improve classification accuracies (Haack et al., 2000; Haack \& Bechdol, 2000; Herold et al., 2004). While the capabilities of RADAR technologies have been examined in several studies, the application and effectiveness of spaceborne L-band ALOS PALSAR data for hydrographic feature mapping in the Caribbean region has not been previously assessed.

\section{Study Area}

The Commonwealth of the Bahamas is composed of 700 islands and nearly 2,500 islets or cays. The country's two most populous cities are the capital, Nassau, located on New Providence Island, and Freeport, located on Grand Bahama Island. Lying between $20^{\circ}$ and $27^{\circ} \mathrm{N}$ and $72^{\circ}$ and $79^{\circ} \mathrm{W}$, the islands of the Bahamas are spread over approximately 260000 square kilometers $\left(\mathrm{km}^{2}\right)$ of the Atlantic Ocean, between Florida and Hispaniola (Figure 1). 


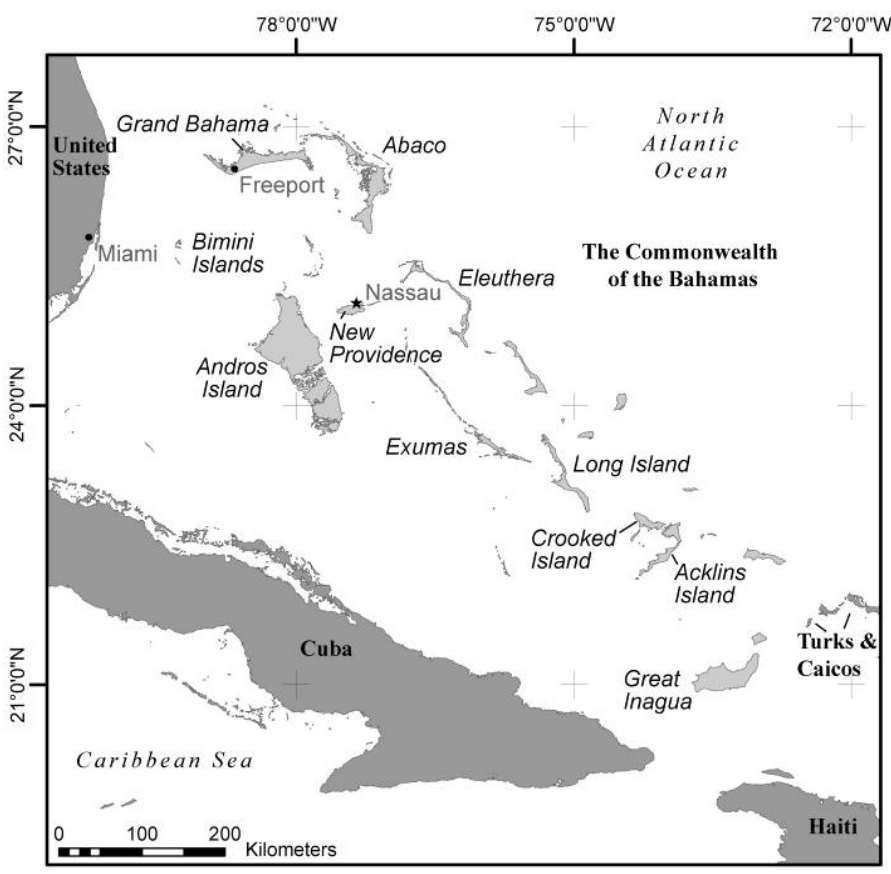

Figure 1. General location map of the Commonwealth of the Bahamas

The climate is semi-tropical marine and is moderated by the warm waters of the Gulf Stream. Annual temperatures range from $15^{\circ} \mathrm{C}$ to $32^{\circ} \mathrm{C}$, with high humidity and prevailing easterly winds. The annual rainfall average is 128.5 centimeters $(\mathrm{cm})$, with the highest amounts of rainfall occurring between May and October.

Two major influencing factors account for fluctuations in water levels on topographically flat coastal environments such as the Bahamas. The first phenomenon is tidal patterns, which affect water areas within the coastal zone. Due to the exceptionally flat, low-lying nature of these islands, a small increase or decrease in the tidal level results in the inundation or exposure of large horizontal areas (Figure 2). In addition, the pressure of high tides pushes the ground water table nearer to the surface. The second phenomenon is rainfall variations, which affect inland lakes and ponds. Such water bodies are particularly influenced by seasonal rainfall, the effects of which are more difficult to estimate (Figure 3).

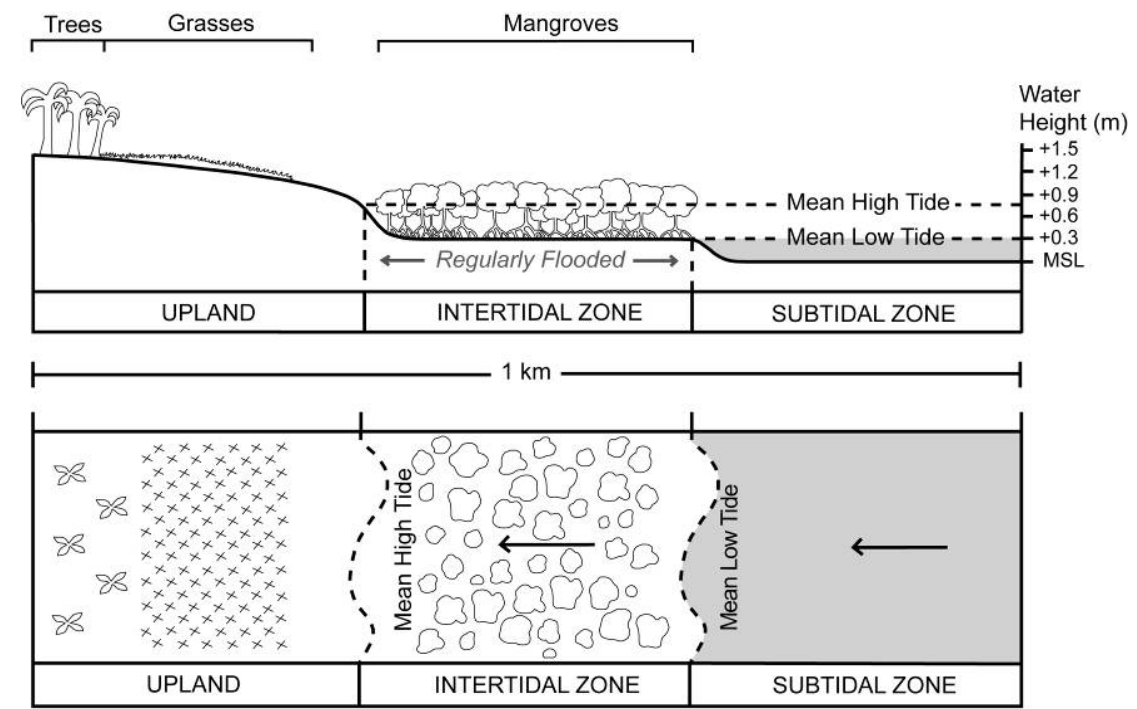

Figure 2. Profile and orthographic figures showing the effects of tidal fluctuations on coastal water bodies with mangrove vegetation 


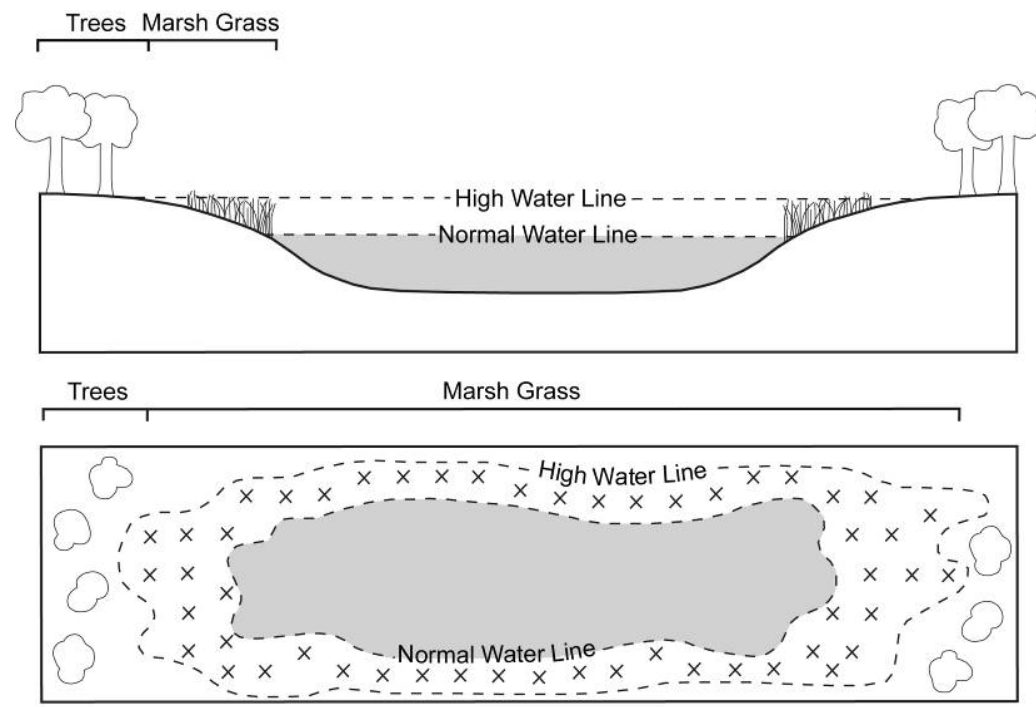

Figure 3. Profile and orthographic figures showing the effects of rainfall variations on inland lakes and ponds vegetated with marsh grasses

Fluctuations in both coastal and inland water levels in the Bahamas are influenced by hazards such as hurricanes, storm surge, and heavy rains. In order to provide a more accurate understanding of the extent of coastal and interior water bodies, the tides and rainfall totals were recorded for the particular dates and times of the imagery and control datasets used in this study (Table 1).

Table 1. Table detailing information on the PALSAR scenes, optical imagery, and data control points used in this study

\begin{tabular}{|c|c|c|c|c|c|c|c|c|c|c|c|c|c|}
\hline Data Type & Coverage & $\begin{array}{c}\text { Spectral } \\
\text { Resolution }(\mathrm{cm})\end{array}$ & $\begin{array}{c}\text { Spatial } \\
\text { Resolution } \\
\text { (m) }\end{array}$ & $\begin{array}{l}\text { Date } \\
\text { (GMT) }\end{array}$ & $\begin{array}{l}\text { Time } \\
\text { (GMT) }\end{array}$ & $\begin{array}{c}\text { Date } \\
\text { (Local) }\end{array}$ & $\begin{array}{l}\text { Time } \\
\text { (Local) }\end{array}$ & $\begin{array}{c}\text { Orbit } \\
\text { Direction }\end{array}$ & $\begin{array}{l}\text { Off Nadir } \\
\text { Angle }\end{array}$ & $\begin{array}{l}\text { Low } \\
\text { Tide }^{\mathrm{a}, \mathrm{b}}\end{array}$ & $\begin{array}{c}\text { Low } \\
\text { Tide } \\
\text { Height } \\
(\mathrm{m})^{c}\end{array}$ & $\begin{array}{l}\text { High } \\
\text { Tide }\end{array}$ & $\begin{array}{c}\text { High } \\
\text { Tide } \\
\text { Height } \\
\text { (m) } \\
\end{array}$ \\
\hline ALOS & New Providence & L-band (23.6) & \multirow{2}{*}{12.655} & 13 June & \multirow{2}{*}{ 03:45:05 } & 12 June & \multirow{2}{*}{ 22:45:05 } & \multirow{2}{*}{ Ascending } & \multirow{2}{*}{34.3} & 02:26:00 & -0.027 & 08:11:00 & 0.738 \\
\hline PALSAR & North & $\mathrm{FBD}(\mathrm{HH}, \mathrm{VV})$ & & 2010 & & 2010 & & & & 14:14:00 & -0.128 & 20:42:00 & 1.027 \\
\hline ALOS & New Providence & L-band (23.6) & \multirow{2}{*}{12.655} & 13 June & \multirow{2}{*}{ 03:45:57 } & 12 June & \multirow{2}{*}{$22: 45: 57$} & \multirow{2}{*}{ Ascending } & \multirow{2}{*}{34.3} & 02:26:00 & -0.027 & 08:11:00 & 0.738 \\
\hline PALSAR & South & FBD $(\mathrm{HH}, \mathrm{VV})$ & & 2010 & & 2010 & & & & 14:14:00 & -0.128 & 20:42:00 & 1.027 \\
\hline \multirow{4}{*}{ Data Type } & \multirow{4}{*}{ Coverage } & \multirow{4}{*}{$\begin{array}{c}\text { Spectral } \\
\text { Resolution }(\mu \mathrm{m})\end{array}$} & \multirow{4}{*}{$\begin{array}{c}\text { Spatial } \\
\text { Resolution } \\
\text { (m) }\end{array}$} & \multirow{4}{*}{$\begin{array}{l}\text { Date } \\
\text { (GMT) }\end{array}$} & \multirow{4}{*}{$\begin{array}{l}\text { Time } \\
\text { (GMT) }\end{array}$} & \multirow{4}{*}{$\begin{array}{c}\text { Date } \\
\text { (Local) }\end{array}$} & \multirow{4}{*}{$\begin{array}{l}\text { Time } \\
\text { (Local) }\end{array}$} & \multirow{4}{*}{$\begin{array}{c}\text { Sun Angle } \\
\text { Azimuth } \\
\left({ }^{\circ}\right)\end{array}$} & Sun & \multirow{4}{*}{$\begin{array}{l}\text { Low } \\
\text { Tide }^{\mathrm{de}, \mathrm{e}}\end{array}$} & Low & & High \\
\hline & & & & & & & & & Angle & & Tide & High & Tide \\
\hline & & & & & & & & & Elevation & & Height & Tide & Height \\
\hline & & & & & & & & & $\left({ }^{\circ}\right)$ & & (m) & & (m) \\
\hline \multirow{2}{*}{ GeoEye-1 } & \multirow{2}{*}{ New Providence } & \multirow{2}{*}{$0.450-0.900$ (MSI) } & \multirow{2}{*}{1.7 (MSI) } & 11 July & \multirow{2}{*}{ 15:49:00 } & 11 July & \multirow{2}{*}{ 10:49:00 } & \multirow{2}{*}{94.7} & \multirow{2}{*}{70.6} & 05:11:00 & 0.125 & 10:09:00 & 0.756 \\
\hline & & & & 2009 & & 2009 & & & & 17:11:00 & 0.180 & 23:21:00 & 0.664 \\
\hline \multirow{4}{*}{ Data Type } & \multirow{4}{*}{ Coverage } & \multirow{4}{*}{ - } & \multirow{4}{*}{ - } & & & & & & & & Low & & High \\
\hline & & & & Date & Time & Date & Time & - & - & Low & Tide & High & Tide \\
\hline & & & & (GMT) & & (Local) & (Local) & & & Tide ${ }^{a}$ & Height & Tide & Height \\
\hline & & & & & & & & & & & (m) & & (m) \\
\hline & & & & 12 & & 12 & & & & $11: 52: 00$ & 0.091 & 05:29:00 & 0.762 \\
\hline GPS Set 1 & New Providence & - & - & March & $15: 30: 00$ & March & 10:30:00 & - & - & & & & \\
\hline & & & & 2010 & & 2010 & & & & 23:57:00 & 0.030 & 17:48:00 & 0.701 \\
\hline GPS Set 2 & New Providence & - & - & 10 June & $17.00 \cdot 00$ & 10 June & $12 \cdot 00 \cdot 00$ & - & - & $12: 51: 00$ & 0.073 & 06:34:00 & 0.683 \\
\hline & & & & 2010 & & 2010 & & & & 12:39:00 & -0.055 & 19:08:00 & 0.945 \\
\hline
\end{tabular}

${ }^{\text {a }}$ Tide times recorded in Local Standard Time

${ }^{\mathrm{b}} \mathrm{NOAA}$ b, 2010

${ }^{\mathrm{c}}$ Tide heights referenced to Mean Lower Low Water (MLLW)

${ }^{\mathrm{d}}$ Mobile Geographics, 2000

${ }^{\mathrm{e}}$ NOAA a, 2009 


\subsection{New Providence Island}

This study focuses on the island of New Providence, in the northern Bahamas. New Providence Island is situated between Andros Island to its west and Eleuthera Island to its east (Figure 4). This island was selected as a study site because it is the most densely populated island in the Bahamas; consequently, the impacts from flooding on this island have the potential to affect a large population.

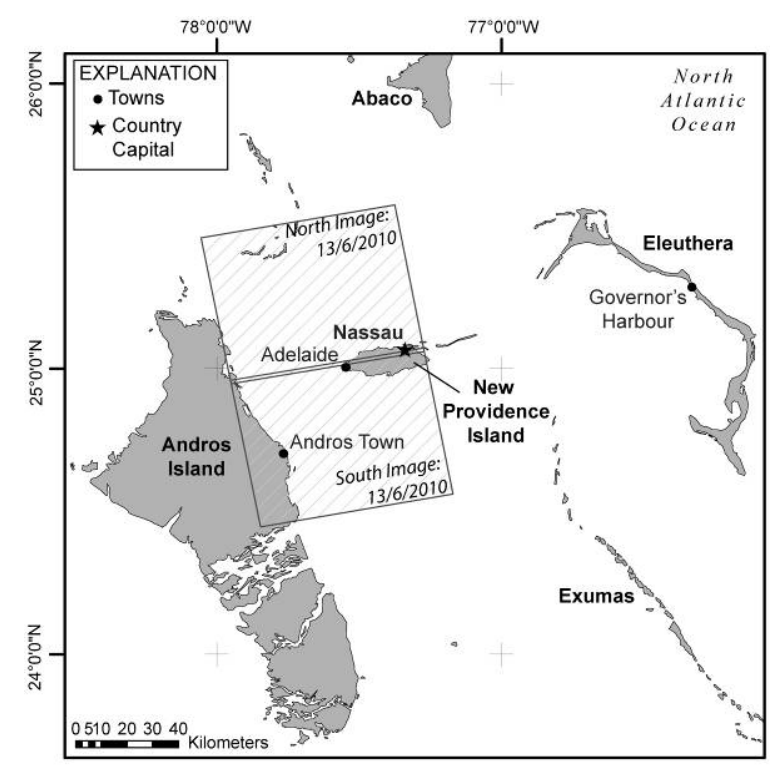

Figure 4. Map showing New Providence and surrounding islands and PALSAR scene coverage

\section{Materials}

\subsection{PALSAR Data Information}

The Japanese Aerospace Exploration Agency (JAXA) launched ALOS in 2006 and operated until 2011, when an electrical malfunction occurred rendering the satellite inoperable. The ALOS satellite carried three remote sensing instruments: the along-track $2.5 \mathrm{~m}$ resolution Panchromatic Remote-sensing Instrument for Stereo Mapping (PRISM), the $10 \mathrm{~m}$ resolution Advanced Visible and Near-Infrared Radiometer type-2 (AVNIR-2), and the variable resolution polarimetric PALSAR. PALSAR operated in four different observation modes: Fine Beam Single (FBS), collecting data in HH at a nominal resolution of $6.25 \mathrm{~m}$; Fine Beam Dual (FBD), collecting data in $\mathrm{HH}$ and $\mathrm{HV}$ at $12.5 \mathrm{~m}$ resolution; Polarimetric mode (POL), collecting data in $\mathrm{HH}, \mathrm{HV}, \mathrm{VV}$, and $\mathrm{VH}$ at between 24 and $89 \mathrm{~m}$ resolution; and a wide-beam ScanSAR mode collecting data at $100 \mathrm{~m}$ (multi look) resolution. PALSAR was a fully polarimetric RADAR sensor, operating in L-band with a 1270-MHz center frequency, 23.6 $\mathrm{cm}$ wavelength, and an incidence angle of $34.4^{\circ}$ in FBS and FBD polarization modes. PALSAR's temporal resolution was once approximately every 46 days.

JAXA is currently in the testing and developmental phase of the PALSAR-2 sensor. PALSAR-2's technological improvements will include higher spatial resolution of up to 1-3 m spotlight mode and a 3-10 m high resolution mode. Additionally, the temporal frequence of PALSAR-2 will improve with a data observable range and a pointable sensor, allowing for more frequent data collection.

ALOS PALSAR RADAR data scene coverage of New Providence was acquired from JAXA via the Alaska Satellite Facility (ASF). Two FBD polarization PALSAR data scenes were purchased with coverage of New Providence Island (Figure 4). Both of these images were collected on 13 June 2010. This date was chosen because there had been no remarkable rainfall before or during the collection of the data, and it coincided with field work conducted on New Providence (Table 1).

\subsection{Optical Satellite Imagery}

Optical satellite imagery was incorporated and used as a baseline for identifying water features on New Providence Island. An image collected by the GeoEye-1 satellite was used to develop training sites for areas representing open water, to assist with the RADAR mapping technique (Table 1). At $1.7 \mathrm{~m}$ multispectral 
resolution, this image provides a high-resolution natural color and near-infrared image of the island, from which different land cover features were identified. The image was also used to develop water control datasets, against which the accuracy of the RADAR mapping method was assessed.

\subsection{Data Control Points}

Datacontrol points were gathered to verify and validate the presence, type, and depth of water features visible in the optical satellite imagery.Field work was conducted on New Providence from 10-13 March 2010 and again from 7-13 June 2010 (Table 1). Twenty-five field sites composed of varying types of inland and coastal hydrographic features were visited (Figure 5). The data control points were regionally concentrated along the northeastern, western, and southwestern coasts, as well as throughout several interior locations near inland water bodies. At each location, data were collectedto document surrounding land cover features, current atmospheric conditions, water depth, and vegetation type and height.

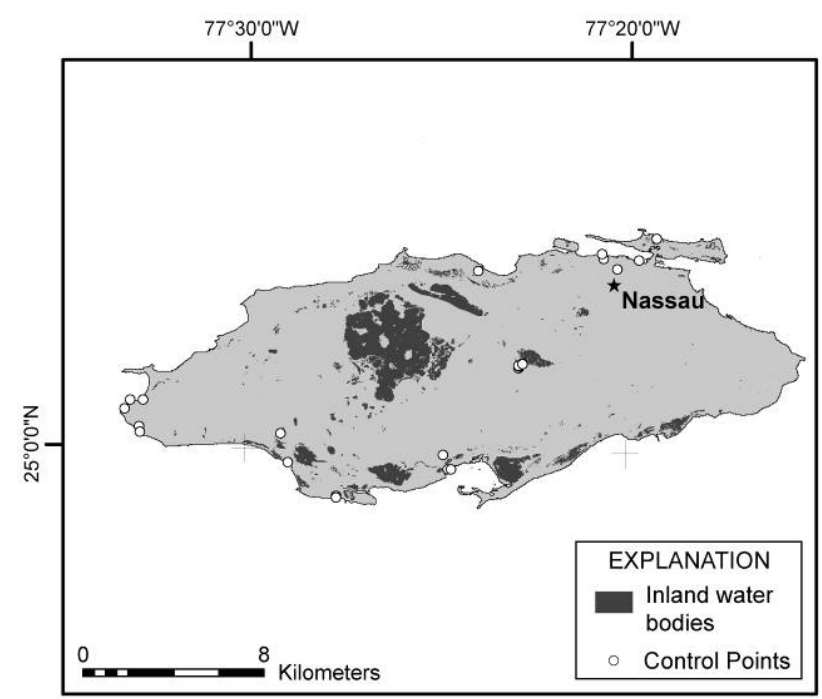

Figure 5. Map showing the location of data control points collected during field work on New Providence Island

\subsection{Water Control Datasets}

A two-step approach was used to compile a water bodies map for checking the accuracy of the PALSAR water mapping results. First, an unsupervised image classification was performed using the near-infrared band of the optical imagery, in which water areas appear as dark reflective surfaces. The second step was a manual photo interpretation to correct the classification, add known water bodies based on data control points which were not correctly classified, and correct areas obscured by cloud cover. Because the optical imagery used in this study was collected 13 months prior to the collection of the RADAR data, the data control points were used to validate the water bodies map to ensure that areas were correctly classified and temporally accurate. In this way, the final control datasets, based largely on the optical imagery, were assured to be accurate for the analysis of the RADAR data.

Two separate control datasets were created. The first is a land-water mask of the entire island, its inland water bodies, and surrounding bays and ocean areas. The second control dataset was developed by clipping the complete control dataset to only inland water bodies, using a vector dataset of the coastline of New Providence. The former was used as an overall measure of the threshold technique's ability to detect the presence of any type of water, while the latter was developed as a means of testing the approach's ability to extract small and seasonal inland water bodies, without including large expanses of ocean which may bias the comparative statistical results.

\subsection{Tropical Rainfall Measuring Mission (TRMM) Data}

Due to the lack of available rainfall data and instrumentation on New Providence Island, data from the Tropical Rainfall Measuring Mission (TRMM) satellite were used to estimate the precipitation totals for New Providence during the time of PALSAR imagery collection. Launched on 28 November 1997, TRMM is a joint operation between the National Aeronautics and Space Administration (NASA) and JAXA, designed to improve estimates 
of precipitation in the tropics and sub-tropics (JAXA). The TRMM data used in this study was collected between 12 June 2010 and 13 June 2010, and recorded 1.6 millimeters $(\mathrm{mm})$ of rainfall during this time period.

\section{Methodology}

\subsection{Processing the RADAR Data}

ASF's MapReady software Version 2.3.6 was used to pre-process the PALSAR data, geocode it into the UTM zone $18 \mathrm{~N}$ projection (WGS84 datum), and apply radiometric corrections. The data were then converted into calibrated backscatter coefficient values (sigma) and scaled to $\mathrm{dB}$, and the calibrated data were exported into a 32 bit floating point GeoTiff format.

\subsection{Determining the Water Threshold for New Providence Island}

In order to classify the RADAR data into areas of water and land, a threshold value for water was identified based on the backscatter coefficients of the RADAR data. The thresholding approach is frequently used to distinguish flooded and non-flooded areas in RADAR imagery with reliable results (Martinis et al., 2009). To determine the threshold value, seven training sites for water were defined in a GIS using the GeoEye-1 imagery of New Providence Island as an image base layer. The training sites are approximately 10000 meters squared $\left(\mathrm{m}^{2}\right)$ in area or greater, and the edges of the selected water bodies were excluded during their delineation to further ensure that vegetation and edge effects were not present.Basic statistics of the backscatter values were calculated for each of the training sites in both the HH and HV datasets of New Providence. The statistical values were then averaged for all of the training sites. The result was a mean backscatter value for each statistic (Table 2).

The average mean plus the average standard deviation $(\overline{\mathrm{x}}$ mean $+\overline{\mathrm{x}}$ std $)$ provides the broadest interpretation of surface water by offering a wide range of RADAR backscatter values. This range of values accounts for water areas which have higher backscatter coefficients due to surface anomalies created by wind or wave action, which often affect open water areas, or the presence of emergent vegetation, often located at the edge of water bodies.

Table 2. Table showing the calculated statistics used to determine the water threshold

\begin{tabular}{|c|c|c|c|c|c|c|c|}
\hline \multicolumn{8}{|c|}{ HH } \\
\hline Training Site & Min & Max & Range & Median & Mean & STD & Mean+STD \\
\hline 1 & -25.00 & -14.00 & 11.00 & -19.00 & -18.89 & 1.72 & -17.17 \\
\hline 2 & -29.00 & -8.00 & 21.00 & -23.00 & -23.45 & 2.42 & -21.03 \\
\hline 3 & -29.00 & -17.00 & 12.00 & -24.00 & -23.41 & 2.24 & -21.17 \\
\hline 4 & -29.00 & -21.00 & 8.00 & -25.00 & -24.72 & 1.65 & -23.07 \\
\hline 5 & -27.00 & -12.00 & 15.00 & -20.00 & -19.81 & 2.18 & -17.63 \\
\hline 6 & -30.00 & -20.00 & 10.00 & -26.00 & -25.64 & 1.69 & -23.95 \\
\hline 7 & -15.00 & -3.00 & 12.00 & -8.00 & -8.26 & 3.15 & -5.12 \\
\hline Mean & -26.29 & -13.57 & 12.71 & -20.71 & -20.60 & 2.15 & -18.45 \\
\hline \multicolumn{8}{|c|}{ HV } \\
\hline 1 & -30.00 & -25.00 & 5.00 & -29.00 & -28.26 & 1.06 & -27.20 \\
\hline 2 & -30.00 & -17.00 & 13.00 & -28.00 & -27.72 & 1.89 & -25.83 \\
\hline 3 & -30.00 & -25.00 & 5.00 & -28.00 & -28.12 & 1.03 & -27.09 \\
\hline 4 & -30.00 & -24.00 & 6.00 & -28.00 & -27.70 & 1.31 & -26.39 \\
\hline 5 & -30.00 & -24.00 & 6.00 & -28.00 & -27.78 & 1.24 & -26.54 \\
\hline 6 & -30.00 & -24.00 & 6.00 & -29.00 & -28.66 & 0.93 & -27.74 \\
\hline 7 & -27.00 & -16.00 & 11.00 & -23.00 & -22.15 & 2.44 & -19.71 \\
\hline Mean & -29.57 & -22.14 & 7.43 & -27.57 & -27.20 & 1.41 & -25.78 \\
\hline
\end{tabular}

For the HH image, $\bar{x}$ mean $+\bar{x}$ std $=-18.45$, and for the HV image $\bar{x}$ mean $+\bar{x}$ std $=-25.78$. These figures were further rounded down to create the most comprehensive threshold. Consequently, the water threshold value 
applied to the HH image was -18 , and the threshold value applied to the HV image was -25 . The HH and HV images were classified, using these threshold values, into binary images in which an output value of 0 represented land and an output value of 1 represented water.

\subsection{Image Classification of New Providence Island}

The binary HH and HV images were subsequently added together, generating a new dataset divided into three classes: 0,1 , and 2 . The value 0 represented land, 1 represented areas classified as water in either the $\mathrm{HH}$ or $\mathrm{HV}$ image, and a value of 2 represented areas classified as water in both the HH and HV images. This image was then reclassified into a new binary image, in which the 1 and 2 value categories were merged to both represent water. Choosing to combine the 1 and 2 value categories provided the greatest retention of water areas in the classified dataset. Choosing to exclude the pixels reclassified as 1 would result in a more conservative selection of pixels classified as water. The reclassified raster image was converted to polygons, which produced a vector coverage of inundated areas, allowing for further analysis, such as flood mapping.

\subsection{Error Calculation}

The two water control datasets were resampled to a pixel size of $12.655 \mathrm{~m}$ to match the spatial resolution of the FBD PALSAR data and were converted to a raster. The datasets were reclassified so that areas defined as land were assigned a value of 50 and areas defined as water were assigned a value of 100 . The reclassified RADAR image was subtracted from the control water dataset, yielding a new raster dataset in which pixels were classified into one of four categories: 49 (the pixel was defined as water in the RADAR image and land in the control dataset), 50 (the pixel was defined as land in both datasets), 99 (the pixel was defined as water in both datasets), or 100 (the pixel was defined as land in the RADAR image and water in the control dataset).

\section{Results and Discussion}

The accuracy of the classification of water was analyzed through the use of classification error matrices. Matrix A tests the results of the RADAR dataset containing the seven training sites, Matrix B tests the results of the RADAR dataset containing both inland and ocean water bodies, and Matrix $\mathrm{C}$ tests the results of the RADAR dataset containing only inland water bodies. The matrices compare the results of known control data extracted from the GeoEye-1 imagery to the results of the RADAR data classification, on a pixel by pixel basis. A producer's accuracy, user's accuracy, and overall accuracy were calculated for areas classified as land and areas classified as water, in each matrix (Jensen, 2004). In Matrix A, the producer's, user's, and overall accuracies for water features were each over 99\%. In Matrix B, the producer's accuracy for water was $91.51 \%$, the user's accuracy was $90.99 \%$, and the overall accuracy was $93.88 \%$. Meanwhile, in Matrix C, the producer's accuracy for water was $72.00 \%$, the user's accuracy was $61.82 \%$, and the overall accuracy was $92.98 \%$ (Table 3). 
Table 3. Table showing the results of the classification error matrices A, B, and C

\begin{tabular}{|c|c|c|c|}
\hline \multicolumn{4}{|c|}{ Error Matrix A } \\
\hline & \multicolumn{3}{|c|}{ Training Sites Data Set } \\
\hline & Land (pixels) & Water (pixels) & Row Total (pixels) \\
\hline \multicolumn{4}{|l|}{ Classification Data } \\
\hline Land (pixels) & 3 & 36 & 39 \\
\hline Water (pixels) & 5 & 4234 & 4239 \\
\hline \multirow[t]{3}{*}{ Column Total (pixels) } & 8 & 4270 & 4278 \\
\hline & \multicolumn{3}{|c|}{ Land Cover Type } \\
\hline & Land $(\%)$ & Water $(\%)$ & Combined $(\%)$ \\
\hline \multicolumn{4}{|l|}{ Accuracy Type } \\
\hline Producer's & 37.5 & 99.15 & 68.33 \\
\hline User's & 7.69 & 99.88 & 53.785 \\
\hline Overall & \multicolumn{3}{|c|}{99.04} \\
\hline \multicolumn{4}{|c|}{ Error Matrix B } \\
\hline \multicolumn{4}{|c|}{ Control Set Data } \\
\hline & Land (pixels) & Water (pixels) & Row Total (pixels) \\
\hline \multicolumn{4}{|l|}{ Classification Data } \\
\hline Land (pixels) & 1129427 & 53945 & 1183372 \\
\hline Water (pixels) & 57530 & 581160 & 638690 \\
\hline \multirow[t]{3}{*}{ Column Total (pixels) } & 1186957 & 635105 & 1822062 \\
\hline & \multicolumn{3}{|c|}{ Land Cover Type } \\
\hline & Land $(\%)$ & Water $(\%)$ & Combined $(\%)$ \\
\hline \multicolumn{4}{|l|}{ Accuracy Type } \\
\hline Producer's & 95.15 & 91.51 & 93.33 \\
\hline User's & 95.44 & 90.99 & 93.22 \\
\hline Overall & & 93.88 & \\
\hline
\end{tabular}

\begin{tabular}{lccc}
\hline \multicolumn{4}{c}{ Error Matrix C } \\
\hline & \multicolumn{3}{c}{ Control Set Data } \\
\hline & Land (pixels) & Water (pixels) & Row Total (pixels) \\
\hline Classification Data & \multicolumn{3}{c}{1163202} \\
\hline Land (pixels) & 1128292 & 34910 & 149819 \\
Water (pixels) & 57199 & 92620 & 1313021 \\
Column Total (pixels) & 1185491 & 127530 & Combined (\%) \\
\hline \multicolumn{4}{c}{ Land Cover Type } \\
\hline \multicolumn{4}{c}{ Water (\%) } \\
\hline Accuracy Type & Land (\%) & 72.00 \\
\hline Producer's & 95.17 & 61.82 & 79.41 \\
User's & 96.99 & \multicolumn{3}{c}{} \\
Overall & \multicolumn{3}{c}{} \\
\hline
\end{tabular}


After comparing the results of the RADAR data classification to the control dataset, it appears that the RADAR data thresholding methodology works best for large, static bodies of water with little emergent vegetation. Lake Killarney, located just east of the international airport on New Providence is roughly $900000 \mathrm{~m}^{2}$ in area and is surrounded by several smaller lakes (Figure 6). The RADAR data correctly classified 94.3\% of the water's surface area.
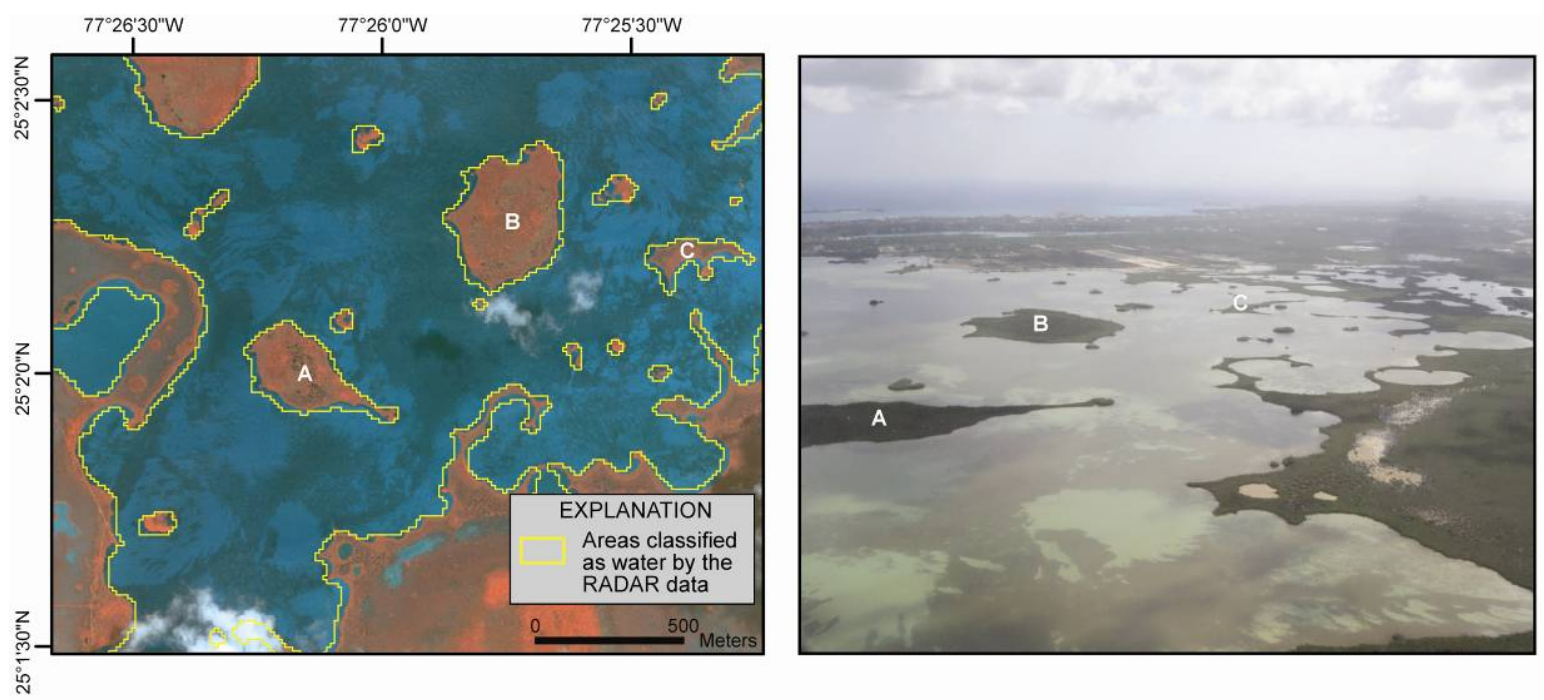

Figure 6. A portion of Lake Killarney as classified by the RADAR data, compared to an oblique aerial photograph of the lake

Lower accuracies were achieved for small, seasonally inundated areas with significant amounts of emergent vegetation, the extents of which fluctuate according to precipitation rates. As the surface area of water bodies decreases, the accuracy of the RADAR classification also decreases. For control water bodies with surfaces areas of $25000 \mathrm{~m}^{2}$ or greater, the accuracy of the RADAR classification ranges from $92 \%$ to $100 \%$. For intermediate sized water bodies $\left(10000-25000 \mathrm{~m}^{2}\right)$, the classification accuracy is $85 \%$. Small water bodies $\left(2,500-10000 \mathrm{~m}^{2}\right)$ have a classification accuracy of $63 \%$, and very small water bodies (less than $2,500 \mathrm{~m}^{2}$ ) have a classification accuracy of only $6 \%$.Wilson's Pond, centrally located on New Providence, is an example of a water body which exhibits fluctuations in surficial areal extent (Figure 7). At Wilson's Pond, the RADAR data correctly classified only $28.9 \%$ of the surface area as compared to the control data. Field investigations conducted three days prior to the acquisition of the RADAR data showed open water present at Wilson's Pond at a depth of greater than $15 \mathrm{~cm}$ and not obscured by vegetation. In contrast, Harold's Pond (Figure 7), located $500 \mathrm{~m}$ to the east, is larger and less seasonally influenced than Wilson's Pond, and the classification results show an accuracy rate of $80.7 \%$.For water bodies with variable surface areas, it is ideal to have a control dataset acquired close to the date of the RADAR data. In this study, the water control dataset was derived from optical satellite imagery acquired nearly one year before the RADAR data; however, data control points collected on the ground within 1-3 days of the RADAR data were used as further verification of the accuracy of the optical image-derived control dataset. 


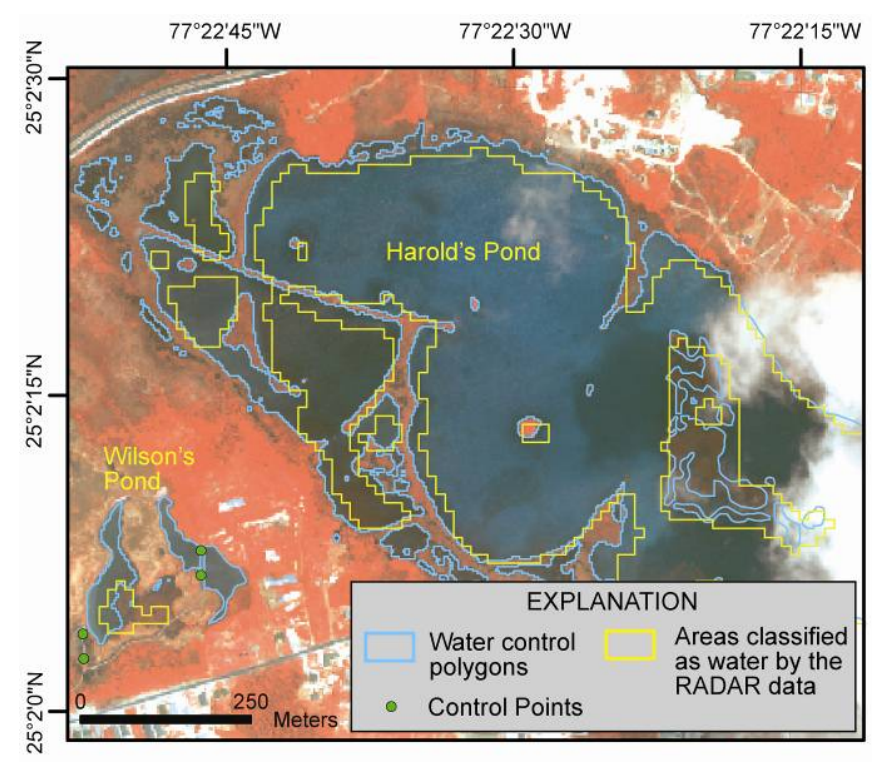

Figure 7. A comparison of the RADAR data and control data's classifications of Wilson's and Harold's Ponds

The presence of vegetation poses another potential problem when using RADAR data to classify water. This is particularly true when dense terrestrial and wetland vegetation are present near a small water body. For example, Jaws Beach pond has a surface area of roughly $9,000 \mathrm{~m}^{2}$, and is heavily vegetated with emergent marsh grasses (Figure 8 ). The RADAR data failed to classify any pixels within this area as water.
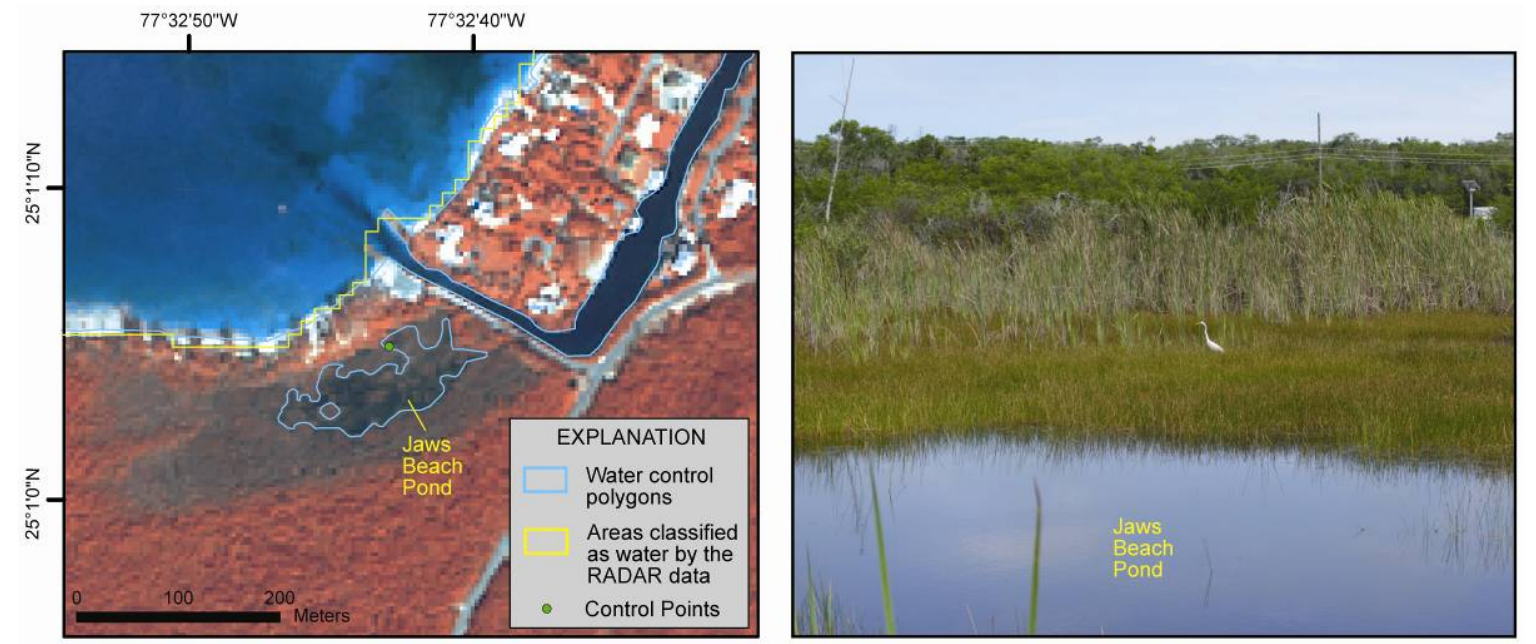

Figure 8. The RADAR data and control data's classifications of Jaws Beach Pond, as compared to a photograph of the pond

When the standard deviation of surface height of the terrain increases above $3.575 \mathrm{~cm}$ due to PALSAR data's $23.6 \mathrm{~cm}$ wavelength and $34.4^{\circ}$ incidence angle (Equation 2), the backscatter values increase. This limits PALSAR's utility for mapping small water features containing emergent wetland vegetation and/or surrounding terrestrial vegetation. Such water features may contain "mixed pixels" of water and vegetation, and as the pixels are representative of an average backscatter value for the entire pixel $(12.655 \mathrm{~m})$, mixed pixels may be misclassified by the thresholding technique. The presence of vegetation within and surrounding water bodies contributes to higher backscatter values as well, due to a corner reflector effect, thus resulting in backscatter values that are higher than the threshold value.

Additionally, in several cases, the RADAR data misclassified large tracts of land as water. Many of these 
locations were visited during field work or examined using optical imagery and were verified as being land. Confusion occurs when the RADAR data detects other smooth landscapes with little to no variation in surface height. Such landscapes include golf courses, as well as land cleared for new development and transportation infrastructure such as roads and the airport's runway and adjacent paved surfaces.

\section{Conclusion}

A need has been identified in the Caribbean region for a basic methodology to assist with the mitigation and response to flood hazards. The goal of this study was to test a simple, practical, and replicable methodology that could be used by governments and hazards managers in the region to develop pre-event baseline and post-event inundation maps. This study applied a thresholding methodology to map water bodies from ALOS PALSAR FBD RADAR data for two image scenes covering New Providence Island in the Commonwealth of the Bahamas.

The thresholding algorithm proved to be over $99 \%$ accurate when classifying the training sites, and the classification accuracy of moderate to large perennial water bodies (greater than $10000 \mathrm{~m}^{2}$ ) was consistently over $85 \%$. However, small, ephemeral wetlands (less than $10000 \mathrm{~m}^{2}$ ) are difficult to classify due to their small size and the frequent presence of emergent vegetation of variable height and density.

The results demonstrate that PALSAR FBD mode data is an effective tool for the identification of coastal and inland water bodies in the Bahamas, for moderate resolution mapping purposes. In particular, this technique can be used to develop baseline maps of moderate to large scale water body features, with a high degree of accuracy. The simplicity of the methodology renders it a highly accessible technique which can be implemented by government and hazard mapping agencies as a means of developing a pre-event map database. While the ALOS satellite is no longer operational, the extensive existing PALSAR data archive is an ideal tool for mapping and cataloguing perennial water bodies as part of such a pre-hazard assessment. However, this technique has limited application potential for post-event flood mapping. Mixed pixels, which can arise from the presence of surface water in conjunction with emergent vegetation, as illustrated in this study, or from the presence of infrastructure and man-made features, result in higher backscatter values. As a result, the classification may under-predict the extent of surface water in flooded areas.

PALSAR-2 is currently under development and its enhanced spatial and temporal resolutions will improve the sensor's ability to discriminate finer scale hydrographic features, and therefore may improve classification accuracies. This study highlighted the necessity for an improved methodology aimed at addressing the issue of mixed pixels. One possible approach is to incorporate RADAR surface texture measurements with the thresholding technique, to develop a more robust classification of land cover features. Additionally, conducting pre and post-event RADAR image comparisons would enable practitioners to observe changes in backscatter values due to the effects of rainfall and coastal storm surge. The applications of RADAR data for post-event flood mapping in the Caribbean should continue to be investigated by researchers, as the need within the region is great. RADAR data has the potential to be a valuable tool for such purposes, particularly as higher resolution sensors are developed, improving the effectiveness of the data for detecting water in a variety of environments.

\section{Acknowledgements}

The authors wish to acknowledge the financial support of the U.S. Geological Survey (USGS) and the U.S. Northern Command (USNORTHCOM) and the cooperation and logistical support provided by The Bahamas National Geographic Information Systems Centre (BNGIS).

\section{References}

Campbell, J. B. (2007). Introduction to Remote Sensing (4th ed). New York, NY: Guilford Press.

Haack, B. N., \& Bechold, M. (2000). Integrating multisensor data and RADAR texture measures for land cover mapping. Computers and Geosciences, 26, 411-421. http://dx.doi.org/10.1016/S0098-3004(99)00121-1

Haack, B. N., Herold, N. D., \& Bechdol, M. A. (2000). RADAR and optical data integration for land-use/land-cover mapping. Photogrammetric Engineering and Remote Sensing, 66(6), 709-716.

Herold, N. D., Haack, B. N., \& Solomon, E. (2004). An evaluation of RADAR texture for land use/cover extraction in varied landscapes. International Journal of Applied Earth Observation and Geoinformation, 5, 113-128. http://dx.doi.org/10.1016/j.jag.2004.01.005

Hess, L. L., Melack, J. M., Filoso, S., \& Wang, Y. (1995). Delineation of inundated area and vegetation along the Amazon floodplain with the SIR-C synthetic aperature RADAR. IEEE Transactions on Geoscience and Remote Sensing, 33(4), 896-904. http://dx.doi.org/10.1109/36.406675 
Horritt, M. S., Mason, D. C., Cobby, D. M., Davenport, I. J., \& Bates, P. D. (2003). Waterline mapping in flooded vegetation from airborne SAR imagery. Remote Sensing of Environment, 85, 271-281. http://dx.doi.org/10.1016/S0034-4257(03)00006-3

JAXA. (2007). Tropical Rainfall Measuring Mission "TRMM". Retrieved January 11, 2011, http://www.eorc.jaxa.jp/TRMM/about/outline/outline_e.htm

Jensen, John R. (2004). Introductory digital image processing (3rd ed). New Jersey: Prentice Hall.

Joyce, K. E., Belliss, S. E., Samsonov, S. V., McNeill, S. J., \& Glassey, P. J. (2009). A review of the status of satellite remote sensing and image processing techniques for mapping natural hazards and disasters. Progress in Physical Geography, 33(2), 183-207. http://dx.doi.org/10.1177/0309133309339563

Lang, M. W., Kasischke, E. S., Prince, S. D., \& Pittman, K. W. (2008). Assessment of C-band synthetic aperature RADAR data for mapping and monitoring coastal plain forested wetlands in the Mid-Atlantic region, USA. Remote Sensing of Environment, 112(11), 4120-4130. http://dx.doi.org/10.1016/j.rse.2007.08.026

Lucas, R. M., Mitchell, A. L., Rosenqvist, A., Proisey, C., Melius, A., \& Ticehurst, C. (2007). The potential of L-band SAR for quantifying mangrove characteristics and change: case studies from the tropics. Aquatic Conservation, 17(3), 245-264. http://dx.doi.org/10.1002/aqc.833

Martinez, J. M., \& Le Toan, T. (2007). Mapping of flood dynamics and spatial distribution of vegetation in the Amazon floodplain using multitemporal SAR data. Remote Sensing of Environment, 108(3), 209-223. http://dx.doi.org/10.1016/j.rse.2006.11.012

Martinis, S., Twele, A., \& Voigt, S. (2009). Towards operational near real-time flood detection using a split-based automatic thresholding procedure on high resolution TerraSAR-X data. Natural Hazards and Earth Systems, 9, 303-314. http://dx.doi.org/10.5194/nhess-9-303-2009

Mobile Geographics. (2005). Nassau, New Providence Island, Bahamas. Retrieved January 15, 2011, from $\mathrm{http} / /$ tides.mobilegeographics.com/locations/4062.html?y=2000\&m=11\&d=6

Mumby, P. J., \& Harborne, A. R. (1999). Development of a systematic classification scheme of marine habitats to facilitate regional management and mapping of Caribbean coral reefs. Biological Conservation, 88, 155-163. http://dx.doi.org/10.1016/S0006-3207(98)00108-6

NOAA b. (2010). NOAA Tide Predictions: Nassau, New Providence Island. Retrieved January 15, 2011, from http://tidesandcurrents.noaa.gov/get_predictions.shtml

Pope, K. O., Rey-Benayas, J. M., \& Paris, J. F. (1994). RADAR remote sensing of forest and wetland ecosystems in the Central American tropics. Remote Sensing of Environment, 48(2), 205-219. http://dx.doi.org/10.1016/0034-4257(94)90142-2

Schumann, G., Bates, P. D., Horritt, M. S., \& Matgen, P. (2009). Progress in integration of remote sensing-derived flood extent and stage data and hydraulic models. Reviews of Geophysics, 47, 20. http://dx.doi.org/10.1029/2008RG000274

Showalter, P. S., Ramspott, M., Morton, D., Prosperie, L., \& Walter, L. (1999). The use of remote sensing in detecting and analyzing natural hazards and disasters, 1972-1998: A partially annotated bibliography. Occasional Paper No. 1. San Marcos, Texas: Southwest Texas State University. Retrieved from http://www.worldcat.org/title/use-of-remote-sensing-in-detecting-and-analyzing-natural-hazards-and-disaste rs-1972-1998-a-partially-annotated-bibliography/oclc/043250291

Townsend, P. A., \& Walsh, S. J. (1998). Modeling floodplain inundation using an integrated GIS with RADAR $\begin{array}{llll}\text { and optical } & \text { remote } & \text { sensing. }\end{array}$ http://dx.doi.org/10.1016/S0169-555X(97)00069-X

Ulaby, F. T., Moore, R. K., \& Fung, A. K. (1986). Microwave Remote Sensing: Active and Passive, Vol. III-Volume scattering and emission theory, advanced systems and applications. Dedham, Massachusetts: Artech House, Inc. 